\title{
Donor selection in pre-sensitized patients for renal transplant
}

\section{SR Kankonkar* \\ Tissue Typing Lab, Bombay Hospital, Mumbai, Maharashtra, India}

\begin{abstract}
Abbreviations: Tx: Transplant/Transplantation; +ve: Positive; -Ve: Negative; X Match: Cross match; PRA: Panel Reactive Antibody; AbS: Antibody.
\end{abstract}

\section{Introduction}

The reactivity between HLA antigen of donor and ant-HLA antibody of recipient in pre-transplant assessment is one of the critical factors to determining successful transplantation, especially in renal $\mathrm{Tx}$ [1].

Chronic rejection is a major threat to long term survival of an organ allograft It is presumed that such a rejection is mediated by the Abs development against antigens of allograft and has also been observed that the long-term survival of renal allograft is significantly lower in patients who developed anti HLA antibodies following Tx than in patient that do not develop antibodies.

An acute rejection occurs more often in pts who have been sensitized to HLA antigens by a previous Tx. However, the late chronic rejection is independent of patient's H/o pre-sensitization to HLA antigens.

In such cases Panel Reactive Antibodies (PRA) have an important role on enhancement of an allograft survival in a renal Tx recipient.

\section{Methods}

Of the four techniques viz

1. Use of Panel frozen lymphocytes

2. Use of Panel after 100 fresh cells depending on the frequency of various specificities in a community

3. Use of the flow cytometry

4. LATM antibody detection procedure of One Lambda Inc. LAT M trays are (based on ELISA) that are used to carry PRA estimation with a great accuracy and Luminex (latest technology) to detect donor specific antibodies

$2^{\text {nd }}$ Technique i.e. Panel Reactive Antibodies (PRA) was used against class I \& class II - HLA antigens of known specificities amongst Indian population.

Adopting the above-mentioned technique, a judicial selection of prospective suitable donors was made for the three pre-sensitized patients.

Immuno-suppressive protocol comprised 3 standard drugs regimen (cyclosporine, Azathioprine \& Prednisolone).

\section{Case I}

12-year-old ESRD female patient with H/O SLE (having high titer of antinuclear antibody anti -DNA antibody). She was on regular dialysis (three times a week), her blood group $\mathrm{O} R \mathrm{Rh}+\mathrm{ve}$, and received non- specific multiple transfusions.

\section{HLA typing of the patient}

\section{A1, B8 (BW6), DR3, DQ2, DR52}

$\mathrm{X}$ matching previously carried out at different centers with unrelated donors were controversial

PRA test was carried using DTT at Bombay Hospital was 30\% +ve.

However, it was found PRA100\% +ve with HLA antigen viz. B17 (B57), 80\% +ve with HLA B27 10\% +ve with HLA A28.

Tx was scheduled after selection of competent donor.

37 years old donor with negative cross match who did not have HLA B27, B17 (B57) antigens was selected for Tx, however, Post Tx mild rejection on 6th day was observed which was corrected by OKT3.

Post Tx status was excellent, even after a lapse of 25 years. Later, she got married and led normal life without any problem.

\section{Case II}

45-Year-old multiparous female with history of ESRD, on regular dialysis.

Received non-specific multiple blood transfusions and developed cytotoxic HLA antibodies.

Cross matching (with her family members including her sibs, children, spouse and community relatives etc) were strongly positive (100\%) continuously for long period of time.

She was referred to the Lab at Bombay Hospital. Her serum was found $100 \%$ positive against the panel of cells. This was again repeated (PRA) after $3^{\text {rd }}$ month and found to be $>95 \%$ reactive.

\section{Tissue typing}

HLA A3, A24, B27 (BW4), B40 (BW6)

CW1, CW3

${ }^{\star}$ Correspondence to: SR Kankonkar, Ex HOD, Tissue Typing Lab, Bombay Hospital, Mumbai, Maharashtra, India, E-mail: kankonkar@yahoo.com

Received: February 11, 2019; Accepted: February 25, 2019; Published: February 27,2019 


\section{DR2, DR9, DQ1 \& DQ3, DR51 \& DR53}

PRA was $90 \%$ reactive (came down after treatment and later, she was reported less/no antibodies against following haplotypes/ (antigens)

HLA A31, B40, DR4

HLA A30, A33, B40, DR2

HLA- A30, B13, B40, DR2, DR4

Two donor specific blood transfusions with HLA mismatch (0 match) \& negative cross matched donor were given on ' 0 ' (Zero) day and then on $7^{\text {th }}$ day - X matching results were I strongly +ve.

We selected the Donor from the panel of 100 cells after a gap of 3 months, no blood transfusion was given.

After repeated results of negative $\mathrm{X}$ matching with the same donor, the patient underwent Tx.

\section{Results}

No post- operative complications were reported, creatinine remained under control between 1-1.4 $\mathrm{mg} \%$.

She died after one year due to TBM, Allograft function was well.

\section{Case III}

26 years Male patient with H/o ESRD.

Received allograft from mother. Developed chronic rejection after a year.

The biopsy showed membrano-proliferative glomerulonephritis type 1 in Tx Kidney, and was given massive doses of steroids followed by immunosuppressant and anti- epileptic drugs [2].

\section{HLA Typing}

A3, A31, B8, B40 (B60), B6, C7

\section{DR3, DR6, DQ1, DQ2, DR52}

Developed leukopenia \& rejected allograft. Biopsy showed acute rejection.

PRA was strongly +ve (70\%). Developed cytotoxic antibodies. Developed antibodies against following Haplotypes/or antigens:

HLA A24, B17, B44, DR3, DR7 - 100\%

HLA A1, A11 \& B1- 98\%

HLA B18, B40 - 80\%

Modified DTT treated serum of the patient was tested against the Panel of cell. PRA showed the presence of IgG type of Abs.

Level of PRA came down after 6 months.

HLA DR6 matched donor with -ve X match was selected for retransplantation.

However, he developed HCV infection while waiting for Tx.

Tx was carried out but developed delayed graft function. This was corrected by medication.

Thereafter allograft functioned smoothly for 8 years.

The patient died of viral encephalitis after eight and half years.

\section{Acknowledgements}

I thank my fellow consultants for their help and referring cases to me. I also give thanks to my technical staff.

\section{References}

1. McKenna RM, Takemoto SK, Terasaki PI (2000) Anti-HLA antibodies after solid transplantation. Transplantation 69:319-326. [Crossref]

2. Kissmeyer-NF, Olsen S, Fjeldborg C (1966) Hyperacute rejection of kidney allografts, associated with pre-existing humoral antibodies against donor cells Lancet 2: 662-665. [Crossref]

Copyright: (C2019 Kankonkar SR. This is an open-access article distributed under the terms of the Creative Commons Attribution License, which permits unrestricted use, distribution, and reproduction in any medium, provided the original author and source are credited. 